Abstract-Rockfishes (Sebastes spp.) tend to aggregate near rocky, cobble, or generally rugged areas that are difficult to survey with bottom trawls, and evidence indicates that assemblages of rockfish species may differ between areas accessible to trawling and those areas that are not. Consequently, it is important to determine grounds that are trawlable or untrawlable so that the areas where trawl survey results should be applied are accurately identified. To this end, we used multibeam echosounder data to generate metrics that describe the seafloor: backscatter strength at normal and oblique incidence angles, the variation of the angle-dependent backscatter strength within $10^{\circ}$ of normal incidence, the scintillation of the acoustic intensity scattered from the seafloor, and the seafloor rugosity. We used these metrics to develop a binary classification scheme to estimate where the seafloor is expected to be trawlable. The multibeam echosounder data were verified through analyses of video and still images collected with a stereo drop camera and a remotely operated vehicle in a study at Snakehead Bank, $\sim 100 \mathrm{~km}$ south of Kodiak Island in the Gulf of Alaska. Comparisons of different combinations of metrics derived from the multibeam data indicated that the oblique-incidence backscatter strength was the most accurate estimator of trawlability at Snakehead Bank and that the addition of other metrics provided only marginal improvements. If successful on a wider scale in the Gulf of Alaska, this acoustic remote-sensing technique, or a similar one, could help improve the accuracy of rockfish stock assessments.

Manuscript accepted 21 November 2012. Fish. Bull. 111:68-77 (2013).

doi:10.7755/FB.111.1.6

The views and opinions expressed or implied in this article are those of the author (or authors) and do not necessarily reflect the position of the National Marine Fisheries Service, NOAA.

\title{
Seabed classification for trawlability determined with a multibeam echo sounder on Snakehead Bank in the Gulf of Alaska
}

\author{
Thomas C. Weber (contact author) ${ }^{1}$ \\ Christopher Rooper ${ }^{2}$ \\ John Butler ${ }^{3}$ \\ Darin Jones ${ }^{2}$ \\ Chris Wilson² \\ Email address for contact author: weber@ccom.unh.edu \\ ${ }^{1}$ Center for Coastal and Ocean Mapping \\ University of New Hampshire \\ 24 Colovos Road \\ Durham, New Hampshire 03824 \\ 2 Alaska Fisheries Science Center \\ National Marine Fisheries Service, NOAA \\ 7600 Sand Point Way NE \\ Seattle, Washington 98115 \\ ${ }^{3}$ Southwest Fisheries Science Center \\ National Marine Fisheries Service, NOAA \\ 8604 La Jolla Shores Drive \\ La Jolla, California 92037
}

Rockfish (Sebastes spp.) stocks are difficult to assess because of their propensity to aggregate near the seafloor in areas that are difficult to trawl, such as rocky, cobble, or generally rugged areas. Consequently, data from bottom-trawl surveys conducted in trawlable areas typically are extrapolated to all areas within the boundaries of a survey, regardless of whether the seafloor is trawlable or not (Wakabayashi et al., 1985). Such extrapolation may result in biased biomass indices if, for example, there is a shift in biomass between strata with variable but unknown amounts of untrawlable seafloor (Cordue, 2006). Evidence also indicates that species assemblages differ between trawlable and untrawlable areas (Matthews and Richards, 1991; Jagielo et al., 2003; Rooper et al., 2010), and remote-sensing techniques with acoustic or optical sensors may be able to help identify these differences. Equally important is the need to have a quantitative assessment of those grounds that are trawlable or untrawlable to more accurately estimate the areas where the results of different stock assessment methods are valid.

In many bottom-trawl surveys, trawlability has been assessed through the subjective interpretation of normal-incidence backscatter (echoes) from downward-looking single-beam echo sounders. These backscatter echoes are examined by vessel captains with different levels of experience, with different echo sounders, and with different echosounder settings. Multibeam echo sounders (MBES), which have been successful previously for characterizion of the seafloor for the purposes of mapping habitat and surficial geology (e.g., Kostylev et al., 2001; Goff et al., 2004; Brown and Blondel, 2009), may offer an alternative solution for assessment of trawlability. In addition to the wider, high-precision coverage of the seafloor that results from the use of multiple beams, MBES offer the potential for more accurate discrimination between different types of seafloor substrate (e.g., silt, sand, cobble, and rock) than does the use of downward-looking single beams because of the angle-dependent na- 
ture of the seafloor backscatter strength, $S_{b}$. For example, the normal-incidence (i.e., $0^{\circ}$ incidence angle) $S_{b}$ that would typically be expected for both cobble and fine sand are predicted to be very similar but are appreciably different at increased incidence angles (Fig. 1). Angle-dependent metrics that describe the backscatter from the seafloor have been extracted from MBES data in previous studies to determine the nature of seafloor sediments (e.g., Fonseca and Mayer, 2007).

Seafloor backscatter collected with an MBES, as are the predictions shown in Figure 1, are often treated as the ensemble average of a large number of random realizations of scattered acoustic intensity. Higher order statistics that describe the scattered intensity may also provide information that can be used to characterize the seafloor. Often, the amplitude of the backscatter echoes is expected to follow a Rayleigh distribution, with the underlying assumption that there are a large number of contributors to the backscatter from the seafloor at any instant in time (Jackson and Richardson, 2007). Abraham and Lyons (2002) have linked heavy-tailed, non-Rayleigh distributions of backscatter to a model with a relatively small number of objects on the seafloor that have high levels of backscatter strength. In other words, the details of the probability density function that describe the amplitude of the acoustic echoes are likely to be related to the size and density of the scattering objects and their relative role in the overall scattering response. Measures that indicate non-Rayleigh backscatter may give an indication of distributed cobble or rock that would render a seafloor untrawlable.

In this study, we examined the angle-dependent nature of $S_{b}$, as well as measures of non-Rayleigh distribution of the backscatter and the seafloor rugosity (roughness) derived from bathymetric soundings, in an attempt to discriminate between trawlable and untrawlable seafloors. The data were collected with a Simrad ${ }^{1}$ ME70 MBES (Kongsberg AS, Horten, Norway) at a study area on Snakehead Bank in the Gulf of Alaska, $100 \mathrm{~km}$ south of Kodiak Island (Fig. 2). To test the efficacy of the acoustic measures as classifiers of the seafloor as either trawlable or untrawlable, we compared metrics derived from a MBES with observa-

\footnotetext{
${ }^{1}$ Mention of trade names or commercial companies is for identification purposes only and does not imply endorsement by the National Marine Fisheries Service, NOAA.
}

tions collected with a stereo drop camera (SDC) system (Williams et al., 2010) along with cameras mounted on a remotely operated vehicle (ROV) (Rooper et al., 2012). The results of this comparison were then extracted to the entire multibeam data set that was collected with the Simrad ME70 during our Snakehead Bank surveys.

\section{Methods}

MBES data were collected with a Simrad ME70 MBES mounted on the hull of the NOAA ship Oscar Dyson. The Simrad ME70 was developed specifically for fisheries applications (Trenkel et al., 2008), although it also has been used for bathymetric mapping (e.g., Cutter et al., 2010). The Simrad ME70 is configurable in terms of 1) the number of beams generated, 2) acoustic frequency for each beam, and 3) direction and opening angle of the beams. For our surveys at Snakehead Bank, the Simrad ME70 was configured to generate 31 beams at frequencies ranging from 73 to $117 \mathrm{kHz}$ and at beam opening angles that ranged from $2.8^{\circ}$ to $11.0^{\circ}$. The 31 beams were steered to $0^{\circ}$ in the alongship direction and from $-66^{\circ}$ to $+66^{\circ}$ in the athwartship direction, with the lowest frequencies steered to the highest beam steering angles to mimimize the possibility of ambiguities associated with grating lobes (angular regions within a beam pattern of a transducer array that have equal sensitivity to the main angular region, or lobe, and cause ambiguities in the determination of 


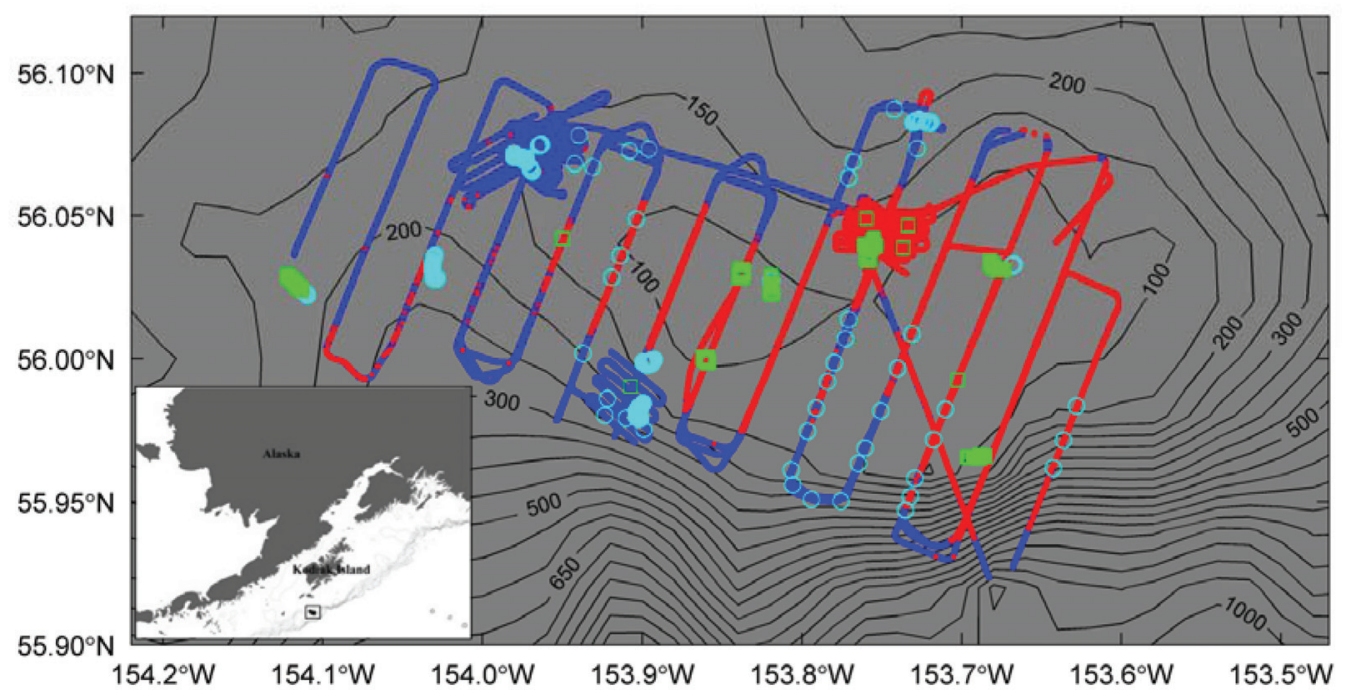

Figure 2

The study area at Snakehead Bank in the Gulf of Alaska, south of Kodiak Island. Bathymetric contours are drawn at 50-m intervals. The locations where data were collected in 2009 with a Simrad ME70 multibeam echo sounder from the large-scale trackline and during focused surveys are shown in red (classified as untrawlable) and blue (classified as trawlable). Camera data collected in 2009 and 2010 with a stereo drop camera and a remotely operated vehicle are shown as green squares (untrawlable) and cyan circles (trawlable).

target angle direction; the occurrence of grating lobes is specific to the design of the transducer array that generates beams). A pulse duration of $1.5 \mathrm{~ms}$ was used for each beam. During transmission and reception, the beam-pointing directions were compensated for pitch and roll of the ship with a GPS-aided inertial motion unit (IMU). The IMU was also used to georeference the data collected with the MBES. The standard target method was used to calibrate the combined transmitreceive sensitivity of each beam (Foote et al., 1987).

In comparison with the Simrad ME70, most hydrographic MBES are capable of generating an order of magnitude more beams with beam opening angles of a fraction of a degree and, therefore, produce a relatively high density of bathymetric soundings and measurements of seafloor backscatter. To achieve a similarly high density of data with fewer beams, we processed the Simrad ME70 data with a hybrid multibeam and phase-differencing technique (Lurton, 2010) that provided hundreds of independent seafloor soundings (each of which was associated with a measure of $S_{b}$ ) over a swath that nominally covered $\pm 60^{\circ}$. At beam angles away from normal incidence, the insonified portion of the seafloor (the area on the seafloor defined by the intersection of the sonar pulse within the beam pattern of the transducer array) acts as a discrete target; therefore, each beam was processed as if it were a phase-measuring bathymetric sonar (Lurton, 2010, section 8.2.3). Because this approach is more accurate at higher incidence angles (Jin and Tang, 1996), a weighted mean amplitude detection (Lurton, 2010, sec- tion 8.3.3) was used for beams with incidence angles of only a few degrees. For our data, the transition between these 2 bottom detection approaches corresponded to an incidence angle of approximately $15^{\circ}$. The raw soundings were then merged with vessel position and attitude data and corrected for refraction through the water column. The georeferenced soundings were used to extract the rugosity in a grid of 25-m squares, or cells, by computing the ratio of the observed surface area within each grid cell to the area of a plane fitted to the same data.

A measure of the acoustic power was associated with each bottom detection and was converted to $S_{b}$ by accounting for system gains and calibration offsets, spherical spreading and absorption in the water column, and area insonified. Area insonified was estimated with the assumption that the seafloor was flat and with the method described by Lurton (2010, section 3.4.3). Applications of these radiometric corrections provided a realization of the angle-dependent seafloor backscatter, which was used to help characterize the seafloor, on each ping. Figure 1 shows predictions of the angle-dependent $S_{b}$ for different substrate types that range from very fine silt to rough rock, on the basis of a scattering model that includes estimates for acoustic impedance, seafloor roughness, and sediment volume scattering strength (APL, 1994). In general, it can be difficult to disambiguate between the different factors that underlie these scattering curves (Fonseca and Mayer, 2007), but they do offer some separation between different substrate types. On the basis of an 
examination of the predictions of $S_{b}$ shown in Figure 1, 3 different metrics that describe $S_{b}$ were used, similar to those of Fonseca and Mayer (2007): the normal-incidence $S_{b}$, the slope of the angle-dependent backscatter within $10^{\circ}$ of normal incidence $\left(S_{b}\right.$-slope), and the average oblique-incidence $S_{b}\left(30^{\circ}<\theta<60^{\circ}\right)$.

The acoustic power associated with each bottom detection also was converted to acoustic backscatter intensity and used to derive an estimate of the scintillation index, $S I$, which is defined here as

$$
S I=\frac{\sigma_{I}^{2}}{\mu_{I}^{2}},
$$

where $\sigma_{I}^{2}$ and $\mu_{I}^{2}=$ the variance and mean of the backscatter intensity, respectively.

The $S I$ is a measure of how the backscatter intensity fluctuates: for Rayleigh-distributed backscatter, the $S I$ is equal to 1 ; for heavier tailed distributions that are a potential indicator of a relatively few strong scatterers contributing to the backscattered echo, the $S I$ would be $>1$. The $S I$ was calculated independently for each beam with a minimum of 50 samples (pings) and then averaged across beams. One important caveat to such $S I$ estimation is that it is dependent on the sonar footprint on the seafloor (Abraham and Lyons, 2004), which changes as a function of incident angle and seafloor depth for MBES. To reduce changes in SI that were associated with the sonar footprint rather than the substrate type, we used only the beam angles between $34^{\circ}$ and $50^{\circ}$ to generate this parameter. This restriction of angles essentially reduced the resolution to that of a single multibeam swath.

The MBES data were compared with image data (both video and still images) from an SDC and a ROV. The SDC contained identical Sony TRD-900 camcorder units (Sony Corp., Tokyo, Japan) capable of collecting progressive scan video images at a pixel resolution of $1280 \times 720$. Both SDC camcorder units were mounted on a sled in an aluminum frame and lowered to the seafloor with a dedicated winch, and illumination was provided by 2 lights mounted above the camera housings inside the aluminum frame (Williams et al., 2010). MBES data also were compared with data collected with a Phantom DS4 ROV (Deep Ocean Engineering, Inc., San Jose, CA). Video footage was recorded from the ROV with a forward-looking color camera (Sony FCB-IX47C module with 470 lines of horizontal resolution and $18 \times$ optical zoom). Two pairs of parallel lasers on the ROV were used to estimate substrate size and horizontal field of view.

Data were collected during 3 cruises conducted at Snakehead Bank, south of Kodiak Island in the Gulf of Alaska (Fig. 2). During the first cruise, the Oscar Dyson and the FV Epic Explorer, a commercial fishing vessel, visited the study site on 4-12 October 2009. Data were collected aboard the Oscar Dyson with the Simrad ME70 and ROV, and data were collected with the stereo drop camera aboard the Epic Explorer. Several repeat large-scale surveys were conducted with The Oscar Dyson along a series of parallel transect lines spaced 2.2 $\mathrm{km}(1.2 \mathrm{nmi})$ apart and $9.3-14.8 \mathrm{~km}(5-8 \mathrm{nmi})$ long. Three of these surveys were used for this analysis. In addition to the large-scale surveys, 4 small-scale, focused surveys were conducted in the same area during the first of the 3 cruises. The focused surveys were designed to achieve "full coverage" (i.e., no unsampled regions of the seafloor) of the seafloor with the Simrad ME70 in areas where a relatively strong indication of fish had been observed in the acoustic data. For the small-scale surveys, transects were $1.9-3.7 \mathrm{~km}$ (1-2 $\mathrm{nmi})$ long and spaced $0.2-0.4 \mathrm{~km}(0.1-0.2 \mathrm{nmi})$ apart (depending on the water depth).

The drop camera was deployed 9 times during the October 2009 cruise, and locations were chosen where the acoustic data indicated that rockfishes were most abundant. During each of the drop-camera deployments, the camera sled moved over the bottom at speeds of $<1.5 \mathrm{kn}$ as the Epic Explorer drifted along transects that lasted up to $1 \mathrm{~h}$ and, as a result, collected relatively dense data in 9 small regions. The horizontal field of view of the drop camera averaged $2.43 \mathrm{~m}$ (standard error of the mean $[\mathrm{SE}]=0.14$ ).

The ROV was deployed in 5 different areas where the acoustic data indicated that rockfishes were most abundant. Each deployment lasted for a few hours. The horizontal field of view for the ROV averaged $2.61 \mathrm{~m}$ $(\mathrm{SE}=0.20)$.

During the other 2 cruises in March and June of 2010 , the study site was revisited and the SDC deployed 51 times aboard the Oscar Dyson. During these additional deployments, the seafloor was recorded in only 1 of the 2 available stereo cameras, preventing collection of stereographic images. Each of these deployments was short: the drop camera was deployed to the bottom for a couple of minutes before it was retrieved to the surface. The resulting images were all from single, small patches $(<25 \mathrm{~m}$ radius $)$ of seafloor, rather than from the drift transects described for the first cruise.

The seafloor substrate observed during the underwater video transects was classified with a commonly used scheme (Stein et al., 1992; Yoklavich et al., 2000). The classification consisted of 2-letter codes for substrate types that denoted a primary substrate with $>50 \%$ coverage of the seafloor bottom and a secondary substrate with 20-49\% coverage of the seafloor. There were 7 identified substrate types: mud (M), sand $(\mathrm{S})$, pebble $(\mathrm{P}$, diameter $<6.5 \mathrm{~cm})$, cobble $(\mathrm{C}$, diameter $6.5-25.5 \mathrm{~cm}$ ), boulder $(\mathrm{B}$, diameter $>25.5 \mathrm{~cm}$ ), exposed low-relief bedrock (R), and exposed high-relief bedrock and rock ridges $(\mathrm{K})$. The size of substrate particles was measured or estimated from a known horizontal field of view $(\sim 2.4 \mathrm{~m})$ for the SDC and estimated with a paired laser system for the ROV. With this classification scheme, a section of seafloor covered primarily in cobble but with boulders over more than $20 \%$ of the surface would receive the substrate-type code cobble- 
boulder $(\mathrm{Cb})$, with the secondary substrate indicated by the lower-case letter. Because the video collected with the SDC and ROV provided a continuous display of substrata, the substrate-type code was changed only if a substrate type encompassed more than 10 consecutive seconds of video.

For this study, the substrate observed in the underwater video transects was further classified as either untrawlable or trawlable with reference to the standard Poly-Nor'eastern 4-seam bottom trawl used in biennial bottom-trawl surveys of the Gulf of Alaska and Aleutian Islands by the Alaska Fisheries Science Center (Stauffer, 2004). The Poly-Nor'eastern bottomtrawl footrope comprised 10-cm disks interspersed with bobbins $36 \mathrm{~cm}$ in diameter. The untrawlable areas were defined as any substrate containing boulders that reached $>20 \mathrm{~cm}$ off the bottom of the seafloor or any substrate with exposed bedrock that was so rough that the standard bottom-trawl footrope would not easily pass over it. Therefore, the trawlable grounds were those areas mostly composed of small cobble, gravel, sand, and mud without interspersed boulders or jagged rocks. The untrawlable grounds were those areas that contained any boulder or high-relief rock substrates. The same experienced observer classified the substrate for both the ROV and SDC video transects.

The video data thus classified were partitioned in a grid of $25-\mathrm{m}$ squares, or cells-a length scale that is a rough estimate for the accuracy of the positioning systems associated with both video systems. The primary and secondary substrate types were given a numeric value based on a nominal substrate size, and each grid cell was assigned substrate types associated with the median values for all data within the cell boundaries. Grid cells also were assigned as trawlable or untrawlable if all data within a cell supported such a classification; otherwise, the grid cell was assigned a "mixed" classification. The gridded video classifications were then compared with the seafloor parameters (e.g., rugosity or normal-incidence $S_{b}$ ) derived from data collected with the Simrad ME70, where both types of data existed at the same position, to provide an indication of how each acoustically derived seafloor parameter was able to discriminate between trawlable and untrawlable areas. This comparison was done for each parameter separately and then done for various combinations of parameters to find a combination of parameters that best discriminated between trawlable and untrawlable substrate. For each parameter, a $t$-test was used to determine whether it was able to distinguish between trawlable and untrawlable seafloor at the significance level of $\alpha=0.05$ (i.e., where erroneous rejection of the null hypothesis is expected $5 \%$ of the time), and values of standard difference (the difference between the sample means divided by the pooled standard deviation) were computed. When combinations of parameters were tested, a best-fit separation (for the goal of minimizing the classification error rate) within the multidimensional parameter space was found through exami- nation of the entire parameter space. To maintain a clear link back to the underlying data distribution, the separation between trawlable and untrawlable was assumed to be a line, plane, or hyperplane (a generalization of a plane into more than 2 dimensions), depending on the dimension of the parameter space.

\section{Results}

The data showed a wide range of values and, presumably, associated substrate types. The shallowest $(<100-$ m) portion of Snakehead Bank contained the highest oblique-incidence $S_{b}$ (approximately $-12 \mathrm{~dB}$ ). This region contained similar values for the normal-incidence $S_{b}$, and small $S_{b}$-slope $\left(<0.75 \mathrm{~dB} /{ }^{\circ}\right)$. Taken together, these data indicate a cobble seafloor on the top of the bank. On the northeastern side of the bank at depths $\sim 200 \mathrm{~m}$, the oblique-incidence $S_{b}$ reached its lowest value of approximately $-30 \mathrm{~dB}$ with a normal-incidence $S_{b}$ of $-15 \mathrm{~dB}$ and $S_{b}$-slope of $\sim 1.1 \mathrm{~dB} /{ }^{\circ}$-values consistent with a substrate composed of very fine silt.

The region with the highest normal-incidence $S_{b}$ $(-10$ to $-7 \mathrm{~dB})$ occurred between $154^{\circ} \mathrm{W}$ and $153.9^{\circ} \mathrm{W}$ and near $56.07^{\circ} \mathrm{N}$ in the northwest region of the bank. The $S_{b}$-slope was also high in this region, reaching up to $1.5 \mathrm{~dB} /{ }^{\circ}$, and the oblique-incidence $S_{b}$ was between $-18 \mathrm{~dB}$ and $-15 \mathrm{~dB}$. These results for the seafloor parameters are confounding, given that the $S_{b}$-slope was large enough to indicate a fine sand or silt, but the normal-incidence and oblique-incidence $S_{b}$ both indicated a coarser sediment or a higher-than-anticipated volume scatter contribution due to heterogeneities or gas (Jones et al., 2012) within the sediment.

The $S I$ shows a complicated pattern that did not appear to be well correlated with any certain substrate type, although there were large (hundreds of meters) contiguous regions that exhibited high $S I$ values (i.e., the data did not appear to be simply random noise). The rugosity levels show the bank to be relatively smooth along the top, except at a sharp transition along its northeastern edge between the 100- and $150-\mathrm{m}$ contours. The rugosity analysis also indicates the appearance of what may be large (wavelength $\sim 150 \mathrm{~m}$ ) sand waves in the extreme southeastern portion of the study area and smaller pockmarks in the southwestern portion of the study area.

The results of a comparison of the seafloor parameters derived from the backscatter data that was collected with the Simrad ME70 and the substrate types derived from the data collected with the SDC and ROV are shown in Figure 3. These data show that, although substrate types $\mathrm{Bb}, \mathrm{Cb}$, and $\mathrm{Gb}$ are difficult to distinguish with backscatter parameters, these 3 types are clearly separate from substrate type Ss. The obliqueincidence $S_{b}$ values for substrate type Ss appeared to be bimodal, with the majority of the values residing between -17 and $-15 \mathrm{~dB}$ and a substantial number of values between -29 and $-26 \mathrm{~dB}$. According to the notional 
A

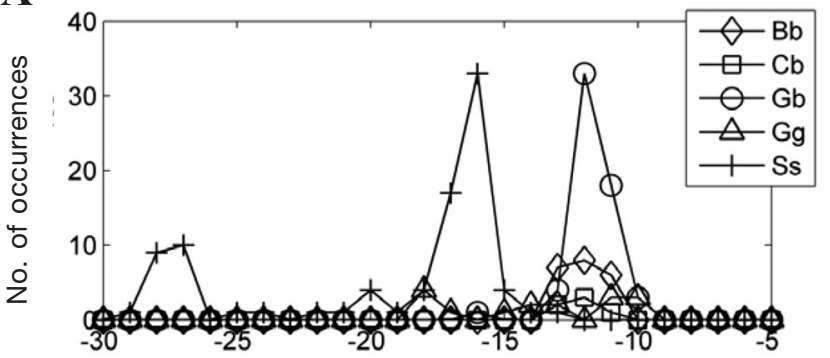

Oblique $S_{b}(d B)$

C

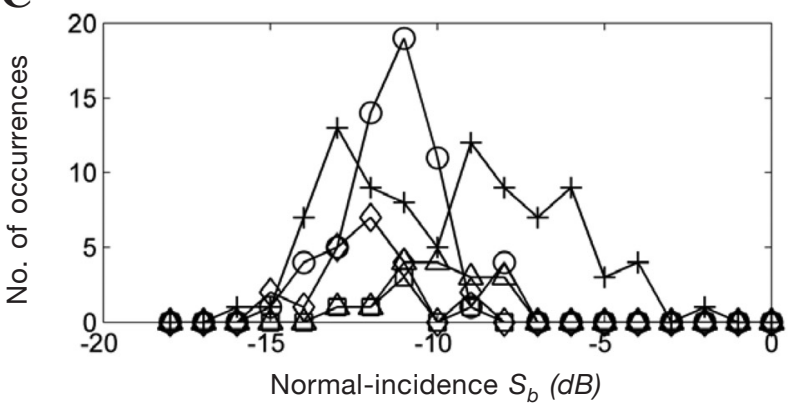

B

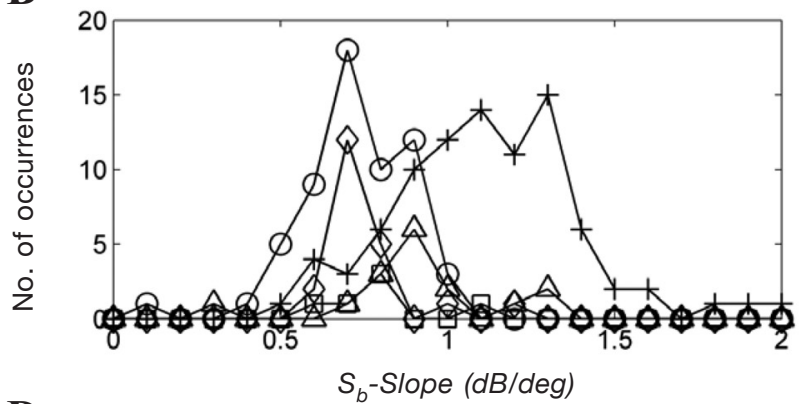

D

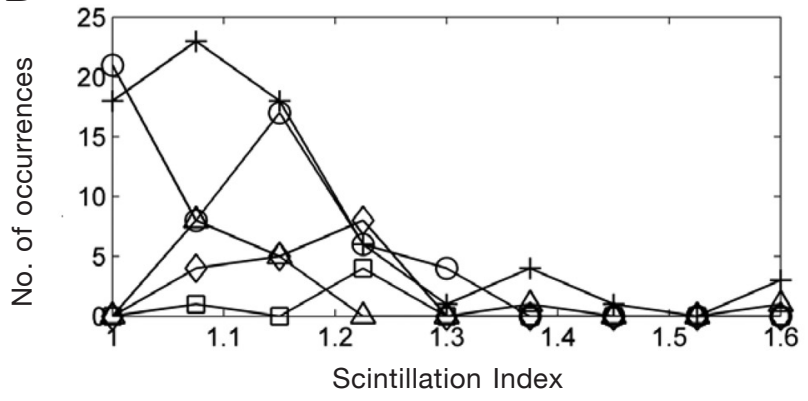

Figure 3

The frequencies of occurrence for major and minor substrate combinations, classified from the data collected in 2009 and 2010 with a stereo drop camera and a remotely operated vehicle as a function of different seafloor characteristics derived from the data collected with a Simrad ME70 multibeam echo sounder. Major (capital letter) and minor (lowercase letter) substrate types included $\mathrm{Bb}=$ boulder; $\mathrm{C}=$ cobble; $\mathrm{Gg}=$ gravel; and $\mathrm{Ss}=$ sand.

values shown in Figure 1, these 2 regions would correspond to sandy gravel and very fine silt, respectively. The lower set of oblique-incidence $S_{b}$ values were found in the deepwater off the northern side of the bank at depths of 200-250 $\mathrm{m}$ and also on the south side of the bank at depths of 120-150 m. On average, the largest $S_{b}$-slope and the widest range of normal-incidence $S_{b}$ were observed on sandy substrate. The normal-incidence $S_{b}$ for areas classified as sandy substrate extended to ranges higher than would be expected, a finding that could be a result of unusually high volumebackscatter caused by gas or heterogeneities within the sediment volume. The harder substrates $(\mathrm{Bb}$ and $\mathrm{Cb})$ all had small $S_{b}$-slope, as expected, and on average had higher $S I$ than the sandy sediments.

To determine how each parameter discriminated between trawlable or untrawlable seafloor, using classified SDC and ROV video data as verification, the frequencies of occurrence for each parameter were extracted for each substrate type (Fig. 4). T-tests indicated that the distributions of trawlable and untrawlable areas of seafloor were distinguishable at the $\alpha=0.05$ significance level (Table 1), although each parameter did not perform equally when discriminating between the 2 classifications. The 3 best individual discriminators were the normal-incidence $S_{b}, S_{b}$-slope, and the oblique-incidence $S_{b}$ with standard differences of 0.74 , 1.12 , and 1.89 , respectively. Of these 3 parameters, the oblique-incidence $S_{b}$ demonstrated the clearest separation between trawlable and untrawlable seafloor, with a boundary at $-13.4 \mathrm{~dB}$. According to modeled data (Fig. 1), this $S_{b}$ level discriminates cobble and rock from gravel, sand, and silt. The $S I$ and rugosity were separated less well with standard differences of 0.25 for each.

With the oblique-incidence $S_{b}$ considered alone, the combined error rate (erroneous classifications of both trawlable and untrawlable seafloor) reached a minimum of $5.6 \%(n=303)$ with a boundary set at $S_{b}=-13.4$ dB. To determine whether this error rate could be lowered, additional parameters derived from the data collected with the Simrad ME70 were linearly combined with the oblique-incidence $S_{b}$. Figure 5 shows the combination of the oblique- incidence $S_{b}$ with each of these other parameters, along with a line that best discriminated between the trawlable and untrawlable classifications. The largest reduction in classification error rate was achieved when the oblique-incidence $S_{b}$ was combined with either the normal-incidence $S_{b}$ or the $S I$, both of which had a marginally improved error rate of $5.0 \%$. When 3 parameters were combined to discriminate between trawlable and untrawlable sea- 


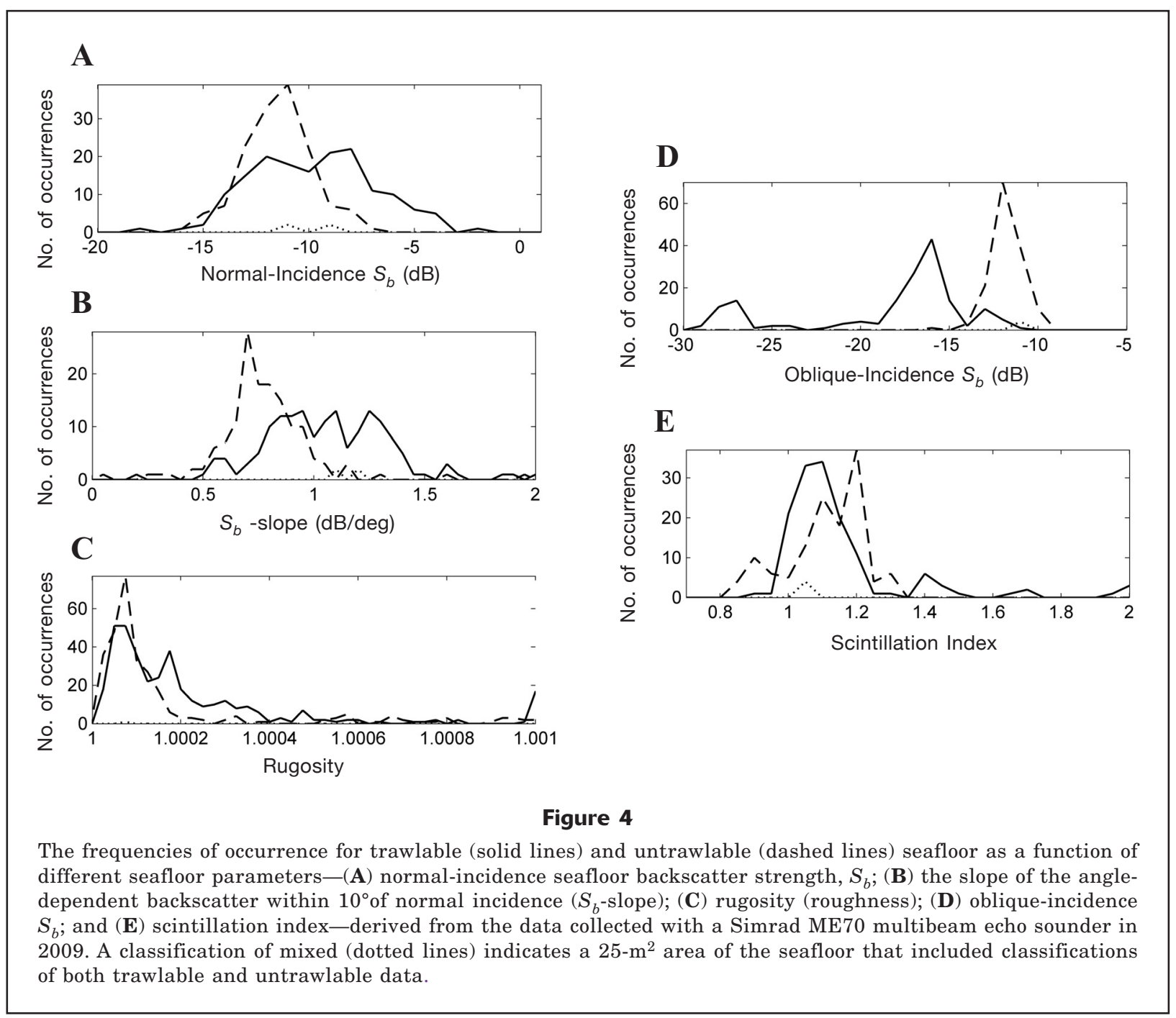

\section{Table 1}

Results of a 2-sample $t$-test and the standard difference in a comparison of trawlable and untrawlable populations for different parameters derived from the data collected with the Simrad ME70 multibeam echo sounder during a cruise in 2009 aboard the NOAA Ship Oscar Dyson. These parameters are normal-incidence seafloor backscatter strength $\left(S_{b}\right)$, oblique-incidence $S_{b}$, the slope of the angle-dependent backscatter within $10^{\circ}$ of normal incidence ( $S_{b}$-slope), scintillation index (SI), and rugosity (roughness).

\begin{tabular}{|c|c|c|c|c|}
\hline & $t$-statistic & $\begin{array}{l}\text { Degrees of } \\
\text { freedom }\end{array}$ & $P$-value & $\begin{array}{l}\text { Standard } \\
\text { difference }\end{array}$ \\
\hline Normal-incidence $S_{b}$ & 6.6 & 260 & $2 \times 10^{-10}$ & 0.74 \\
\hline Oblique-incidence $S_{b}$ & 17.2 & 170 & $4 \times 10^{-39}$ & 1.89 \\
\hline$S_{b}$-slope $\left(0-10^{\circ}\right)$ & 9.9 & 287 & $5 \times 10^{-20}$ & 1.12 \\
\hline SI & 2.1 & 216 & 0.04 & 0.25 \\
\hline Rugosity & 3.6 & 418 & 0.0004 & 0.25 \\
\hline
\end{tabular}

floor, the error rate did not change appreciably except in the case of a combination of the oblique-incidence $S_{b}$, the normal-incidence $S_{b}$, and the $S I$, in which case the class error rate was reduced to $3.8 \%$; similar error rates were found with 4 classes separated by a best-fit hyperplane.

Because only marginal improvements in class error rate were achieved when multiple parameters were combined and maintenance of simplicity in the interpretation of the results was desired, the oblique-incidence $S_{b}$ was chosen as the sole discriminator between the trawlable and untrawlable seafloor at the study site. The classifications of trawlable and untrawlable seafloor classifications area shown in Figure 2 for both the from the Simrad ME70 and the data from the SDC and ROV. The classification based on the data from the Simrad ME70 is accurate throughout most 
A

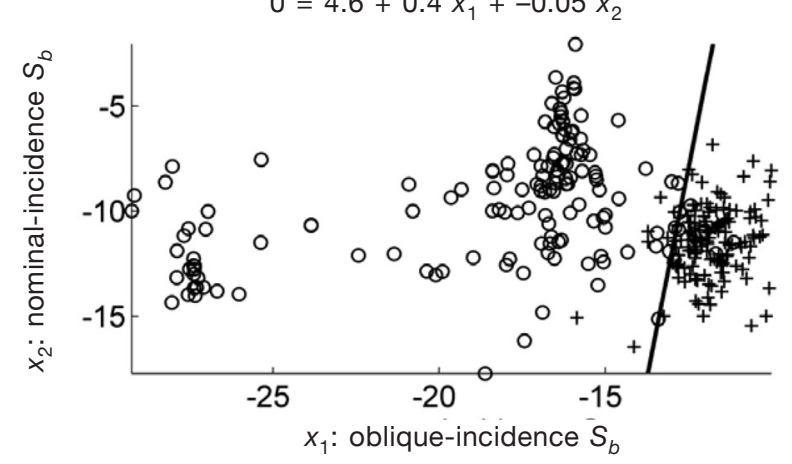

B

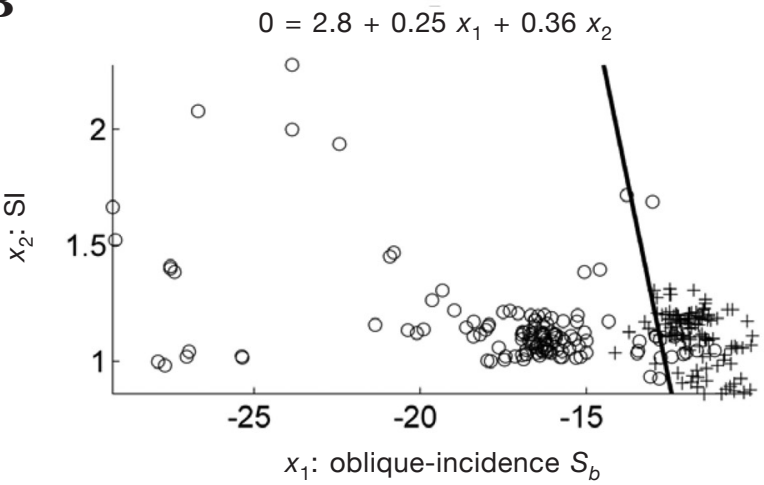

C

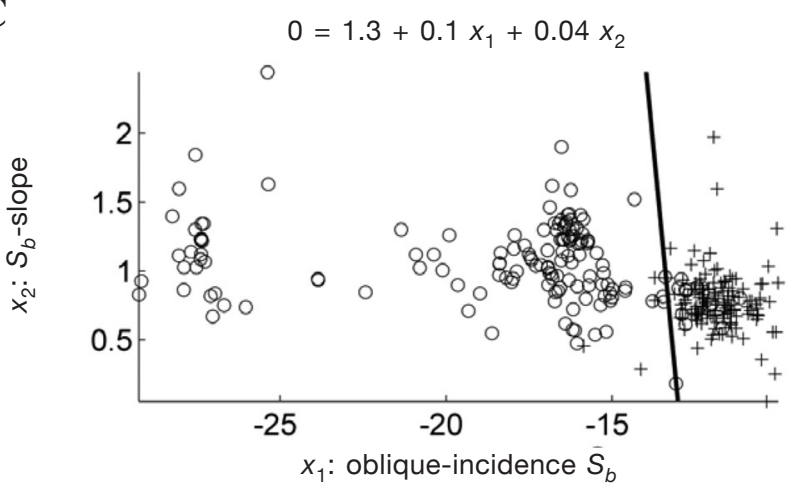

D

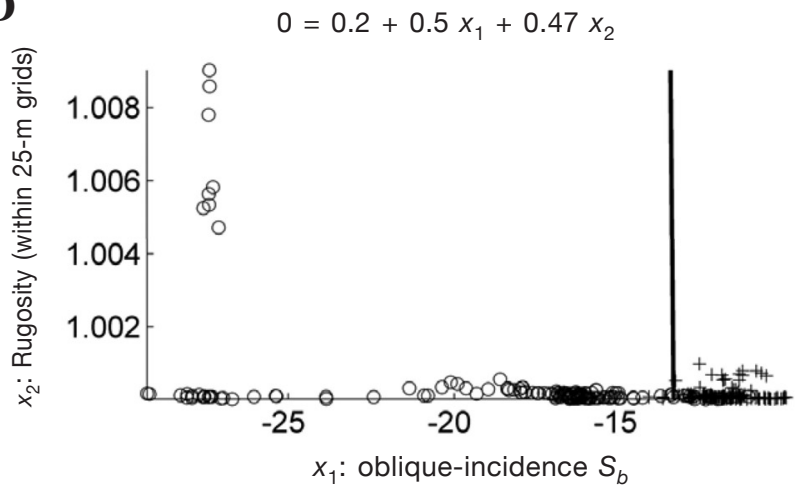

Figure 5

Scatter plots of the oblique-incidence seafloor backscatter strength $\left(S_{b}\right)$ with each of the other seafloor parameters examined in our work and a best-fit line that discriminates between trawlable and untrawlable seafloor. The other seafloor parameters shown here are the $(\mathbf{A})$ normal-incidence $S_{b},(\mathbf{B})$ scintillation index, $(\mathbf{C})$ slope of the angle-dependent backscatter within $10^{\circ}$ of normal incidence $\left(S_{b}\right.$-slope); and (D) rugosity (roughness).

of the study site, and the most obvious error occurred on the north-south transect intersected $153.9^{\circ} \mathrm{W}$ in an area with high oblique-incidence $S_{b}$.

\section{Discussion}

The oblique-incidence $S_{b}$ and the $S_{b}$-slope followed the expected trends when separated into trawlable and untrawlable classes and these trends were verified from video data collected with the SDC and ROV. Untrawlable areas were expected to have a larger oblique incidence $S_{b}$ and $S_{b}$-slope than trawlable areas on the basis of backscatter models (e.g., Fig. 1). The normalincidence $S_{b}$ did not appear to discriminate very well between trawlable and untrawlable seafloor and tended to have a wider distribution of backscatter values than would have been expected on the basis of consideration of the oblique-incidence $S_{b}$ and the modeled values shown in Figure 1. There are several possible reasons for the lack of discrimination with normal-incidence $S_{b}$, including higher-than-expected normal-incidence $S_{b}$ in the sands and silts caused by gas or heterogeneities within the sediment volume in some trawlable areas and higher-than-expected roughness in the areas of cobble and rock that caused a larger-than-anticipated reduction in the normal-incidence $S_{b}$ for some untrawlable areas.

Although quite variable throughout the study area, the mode of the $S I$ was slightly higher for the untrawlable seafloor than it was for the trawlable seafloor. This difference seems plausible when we consider the SI to be a metric for how many scatterers are contributing to the sonar return within a beam footprint. A $S I$ value near 1 suggests that there are a large number of scatterers (i.e., the central limit theorem applies, and the backscatter amplitude is Rayleigh distributed), as might be expected from a sand or silt seafloor. On the other hand, a larger SI indicates that there are only a few dominant scatterers within the beam footprint, as might be expected from a seafloor of cobbles or boulders. Although the data indicate a trend in the correct direction, SI alone has not provided a clear separation between trawlable and untrawlable seafloor (e.g., a 
threshold of 1.2 would result in a high classification error rate).

Rugosity derived from the data collected with the Simrad ME70 was a poor discriminator of trawlable versus untrawlable seafloor, generally with lower values (e.g., smoother seafloor) in areas where the validation data from the SDC and ROV surveys indicate that the seafloor is untrawlable. The areas that contained high values of rugosity generally were dominated by larger scale features: the ridgeline on the northern edge of the bank, the sand waves in the southeast, or the pockmarks in the southwest. It is likely that the spatial resolution of the MBES was insufficient to provide a useful estimate of the rugosity level and that an MBES with higher frequencies and higher resolution might provide more useful results.

The oblique-incidence $S_{b}$ alone provided a low error rate as a discriminator between trawlable and untrawlable seafloor. When combined with the other metrics, it was possible to slightly lower the error rate, but an examination of the scatter plots in Figure 5 indicates that the error rates were not been lowered in any meaningful way. For example, the best-fit line that discriminates between the combination of oblique-incidence $S_{b}$ and normal-incidence $S_{b}$ shows that a combination of high oblique-incidence $S_{b}$ and low normalincidence $S_{b}$ gives a better indication of untrawlable seafloor than high oblique-incidence $S_{b}$ on its own. This finding is contrary to what the modeled seafloor return (Fig. 2) would predict: high oblique-incidence $S_{b}$ and high normal-incidence $S_{b}$ are a better predictor of an untrawlable seafloor. Therefore, it is likely that the marginal improvement in classification error rate with these extra parameters combined is simply a result of variations in the tails of the underlying data distributions. With only marginal improvements $(5.6-3.8 \%)$ in classification error rate when up to 4 parameters are combined, with a hyperplane separating the 2 classes, it is reasonable to choose the simpler approach of using only the oblique-incidence $S_{b}$ as a predictor of trawlable or untrawlable seafloor.

\section{Conclusions}

The results described here indicate that acoustic remote sensing of substrate type with an MBES, and oblique-incidence acoustic $S_{b}$ in particular, offer useful insight into whether the seafloor is untrawlable. This conclusion is in qualitative agreement with the work of Jagielo et al. (2003), who used seafloor backscatter collected with a sidescan sonar as part of an a priori assessment of trawlability (note that much of the sidescan record was collected at oblique incidence angles). Whether these types of acoustic metrics can provide a similar level of confidence regarding the distribution of untrawlable seafloor in areas throughout the entire Gulf of Alaska needs to be determined. If successful on a wider scale, this type of acoustic remote sensing can help refine the interpretation of bottom-trawl surveys. In particular, techniques such as those described here could increase the accuracy in identification of areas with seafloor characteristics similar to areas where bottom-trawl surveys of rockfish were conducted (i.e., areas where results from the trawl surveys can be applied). As a result, the precision and accuracy of biomass estimates from bottom-trawl surveys and their resultant stock assessments would be improved.

\section{Acknowledgments}

Support for this work was provided by the North Pacific Research Board (contribution no. 373). Additional support for T. Weber was provided by NOAA (grant NA05N0S4001153). We would like to acknowledge the crews of the NOAA Ship Oscar Dyson and FV Epic Explorer for their help during data collection. We would also like to thank M. Martin, D. Somerton, and W. Palsson for their thoughtful reviews of this manuscript.

\section{Literature cited}

Abraham, D., and A. Lyons.

2002. Novel physical interpretations of K-distributed reverberation. IEEE J. Oce. Eng. 27(4):800-813.

Abraham, D., and A. Lyons.

2004. Reverberation envelope statistics and their dependence on sonar bandwidth and scattering patch size. IEEE J. Ocean Eng. 29(1):126-137.

APL (Applied Physics Laboratory).

1994. APL-UW High-frequency ocean environment acoustic models handbook, TR9407, IV1-IV36. APL, Univ. Washington, Seattle, WA.

Brown, C., and P. Blondel.

2009. Developments in the application of multibeam sonar backscatter for seafloor habitat mapping. Applied Acoustics 70:1242-1247.

Cordue, $\mathrm{P}$

2006. A note on non-random error structure in trawl survey abundance indices. ICES J. Mar. Sci. 64:1333-1337.

Cutter, G., L. Berger, and D. Demer.

2010. A comparison of bathymetry mapped with the Simrad ME70 multibeam echosounder operated in bathymetric and fisheries modes. ICES J. Mar. Sci. 67(6):1301-1309.

Fonseca, L., and L. Mayer.

2007. Remote estimation of surficial seafloor properties through the application Angular Range Analysis to multibeam sonar data. Mar. Geophys. Res. 28:119-126.

Foote, K. G., H. P. Knudsen, G. Vestnes, D. N. MacLennan, and E. J. Simmonds.

1987. Calibration of acoustic instruments for fish density estimation: a practical guide. ICES Coop. Res. Rep. $144,69 \mathrm{p}$.

Goff, J., B. Kraft, L. Mayer, S. Schock, C. Sommerfield, H. Olsen, S. Gulick, and S. Nordfjord.

2004. Seabed characterization on the New Jersey middle and outer shelf: correlatability and spatial variability of seafloor sediment properties. Mar. Geol. 209:147-172. 
Jackson, D., and M. Richardson.

2007. Chapter 16 in High-frequency seafloor acoustics. 616 p. Springer, New York.

Jagielo, T., A. Hoffmann, J. Tagart, and M. Zimmermann. 2003. Demersal groundfish densities in trawlable and untrawlable habitats off Washington: implications for estimation of the trawl survey habitat bias. Fish. Bull. 101:545-565.

Jin, G., and D. Tang.

1996. Uncertainties of differential phase estimation associated with interferometric sonars. IEEE J. Ocean Eng. 21(1):53-63.

Jones, D. T., C. D. Wilson, A. De Robertis, C. N. Rooper, T. C. Weber, and J. L. Butler.

2012. Rockfish abundance assessment in untrawlable habitats: combining acoustics with complementary sampling tools. Fish. Bull. 110: 332-343.

Kostylev V., B. Todd, G. Fader, R. Courtney, G. Cameron, and R. Pickrill.

2001. Benthic habitat mapping on the Scotian Shelf based on multibeam bathymetry, surficial geology and sea floor photographs. Mar. Ecol. Prog. Ser. 219:121-137.

Lurton, X.

2010. An introduction to underwater acoustics: principles and applications, $2^{\text {nd }}$ ed., 760 p. Springer-Verlag, Berlin.

Matthews, K. R., and L. J. Richards.

1991. Rockfish (Scorpaenidae) assemblages of trawlable and untrawlable habitats off Vancouver Island, British Columbia. N. Am. J. Fish. Manage. 11:312-318.

Rooper, C.N., G. R. Hoff, and A. DeRobertis.

2010. Assessing habitat utilization and rockfish (Sebastes spp.) biomass on an isolated rocky ridge using acoustics and stereo image analysis. Can. J. Fish. Aquat. Sci. 67:1658-1670.
Rooper, C. N., M. H. Martin, J. L. Butler, D. T. Jones, and M.

Zimmermann

2012. Estimating species and size composition of rockfishes in acoustic surveys of untrawlable areas. Fish. Bull. 110: 317-331.

Stauffer, G.

2004. NOAA protocols for groundfish bottom trawl surveys of the nation's fishery resources. NOAA Tech. Mem., NMFS-F/SPO-65, 205 p. Available online at http://spo.nmfs.noaa.gov/tm/tm65.pdf

Stein, D. L., B. N. Tissot, M. A. Hixon, and W. Barss.

1992. Fish-habitat associations on a deep reef at the edge of the Oregon continental shelf. Fish. Bull. 90:540-551.

Trenkel, V., V. Mazauric, and L. Berger.

2008. The new fisheries multibeam echosounder ME70: description and expected contribution to fisheries research. ICES J. Mar. Sci. 65:645-655.

Wakabayashi, K., R. G. Bakkala, and M. S. Alton.

1985. Methods of the U.S.-Japan demersal trawl surveys. In Results of cooperative U.S.-Japan groundfish investigations in the Bering Sea during May-August 1979 (R. G. Bakkala, and K. Wakabayashi, eds.), p. 7-29. Int. North Pac. Fish. Comm. Bull. 44.

Williams, K., C. N. Rooper, and R. Towler.

2010. Use of stereo camera systems for assessment of rockfish abundance in untrawlable areas and for recording pollock behavior during midwater trawls. Fish. Bull. 108:352-362.

Yoklavich, M. M., H. G. Greene, G. M. Cailliet, D. E. Sullivan, R. N. Lea, and M. S. Love.

2000. Habitat associations of deep-water rockfishes in a submarine canyon: an example of a natural refuge. Fish. Bull. 98:625-641. 